\title{
Papers Presented at the 2009 Closed Meeting of the International Hip Society
}

\section{Editorial Comment}

\author{
Miguel E. Cabanela MD
}

Published online: 30 June 2010

(C) The Association of Bone and Joint Surgeons $\mathbb{R} 2010$

This is the third published symposium based on presentations at the International Hip Society closed meeting. The papers included here were presented at the 2009 Summer Meeting of the International Hip Society held in Minneapolis and Rochester, Minnesota, September 2009.

The papers encompass a broad spectrum of topics about the hip. As one would expect today, the bulk of the work presented here revolves around hip arthroplasty and its consequences, including revision surgery.

However, there is a very important non-arthroplasty section including the now much discussed topic of "conservative" hip surgery. Some interesting new ideas are introduced in this section, such as the combination of in situ pinning and arthroscopy to treat slipped capital femoral epiphysis and combined acetabular and femoral osteotomies, including some novel forms of femoral neck osteotomies. Issues of insufficiency fractures of the femoral head and avascular necrosis are given attention by our colleagues from Japan, who present some interesting material on the healing of avascular necrosis after osteotomy procedures.

Primary hip arthroplasty occupies an important part of the symposium. Novel and resurrected old approaches for arthroplasty have been spotlighted lately, sometimes for the wrong reasons, and technical difficulties with these approaches and muscle damage with one versus another approach are discussed. Cemented and noncemented arthroplasties have their proponents in young patients, and it is interesting to observe the different solutions for the young patient on both sides of the Atlantic. Resurfacing, an old concept now in fashion again, could not be omitted

M. E. Cabanela $(\bowtie)$

Department of Orthopedic Surgery, Mayo Clinic College of Medicine, 200 First Street SW, Rochester, MN 55905, USA

e-mail: cabanela.miguel@mayo.edu from the Symposium, and a new issue regarding an unusual impingement problem in resurfacing is broached. Alternative ceramic-ceramic bearings, and highly cross-linked polyethylene were also a de rigueur part of our meeting. Complications of hip arthroplasty are given ample coverage in the symposium. Issues of risk factors for infection and new diagnostic laboratory tests are presented, as well as management of the primary revision causing complication, namely, dislocation; in this paper, methods and tools for management of dislocation which are not yet popular in the United States are discussed.

Finally, revision hip arthroplasty is addressed in the symposium. New directions are shown in the diagnosis of particle disease. Most surgeons perform particulate

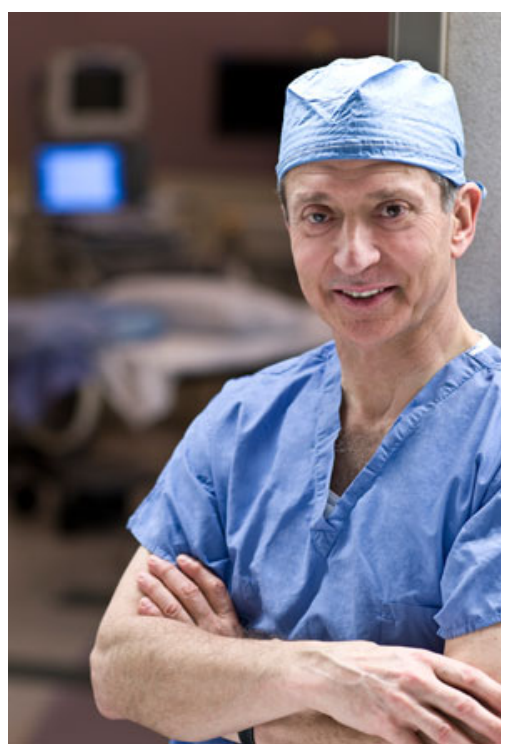

Fig. 1 Miguel E. Cabanela, MD, is shown. 
grafting, but do not know how effective we are; this issue is addressed, as well as the long-term survival of large block grafts. Issues associated with impaction grafting, a technique still frequently used outside of North America, are of value to those using this popular technique as the results seem to be related to how well the technique is performed. Finally, the problem of revising a ceramic-ceramic prosthesis is studied extensively by the group with the largest experience with this friction couple.

The current symposium represents perhaps the best series of papers yet from a meeting of the International Hip
Society. Some of the ideas discussed herein are certainly not popular in North America, but deserve our careful consideration. As has always been the case, the papers have been vastly improved by the invaluable editorial efforts of Dr Richard Brand and the CORR editorial team. To them, I extend my thanks. It is my hope that the reader will enjoy these papers.

Miguel E. Cabanela, M.D. President The International Hip Society 